\title{
Sobre: La Sanidad Militar en la Guerra de África (1859-1860)
}

\section{Sr. Director:}

He leído con atención y con no poco interés el artículo "La Sanidad Militar en la Guerra de África (1859-1860)" escrito por el Coronel Farmacéutico (R) D. L. Gómez Rodriguez publicado en Sanidad Militar 2013; 69 (2) pp. $127-$ 133. La Guerra o la Campaña de 1859-1860 fue un punto de inflexión para la consolidación de la Sanidad Militar como cuerpo militar, tanto por el estado de la sanidad previo al conflicto, como por la demostración que hicieron los sanitarios militares de la necesidad de una sanidad con doctrina y tropas propias, como por el uso de nuevas técnicas como la anestesia en campaña o los escalones de evacuación o el uso de los barco-hospital.

La Sanidad Militar que se enfrenta a la guerra de 1859 es una sanidad sin doctrina, sin apenas organización, sin material adecuado y, sobre todo, cruel e innecesariamente agraviada y desprestigiada por el ejército al que servía. A pesar de ello, se organiza de manera increíblemente eficaz para dar apoyo sanitario a cerca de 50.000 hombres y logra unos objetivos insospechados.

En una época en la que los combates terminan al ponerse el sol, los oficiales médicos españoles, están orgullosos de su trabajo y presumen de que poco después del ocaso, las bajas están todos atendidas, con sus heridas tratadas y operadas, sus fracturas reducidas e inmovilizadas y sus padecimientos atendidos. En estos momentos comienzan a evacuarlas a los hospitales de Ceuta o a los de reunión en las playas, de manera que, en no pocas ocasiones, a las 24 horas, salvo imposibilidad por la meteorología (¡el dichoso levante!), estaban gran cantidad de heridos y enfermos evacuados a los hospitales del Sur peninsular. ¡En 1859!.

No pocas veces, los oficiales médicos y sus practicantes y enfermeros tuvieron que tomar las armas para defender su vida y la de los heridos de sus puestos de socorro de batallón. De los cerca de doscientos oficiales médicos que tomaron parte en la campaña tres fallecieron por el cólera y trece fueron bajas, nueve por cólera y cuatro por bala.

El autor contabiliza entre médicos y farmacéuticos un total de 125; nosotros hemos contabilizado, solamente entre los médicos, 194, prácticamente de todos ellos tenemos la filiación, graduación y destino durante la campaña ${ }^{1}$.

Hay tres autores "de cabecera" para estudiar el papel de la sanidad militar durante esta campaña:

- Antonio Población Fernández con su Historia Médica de la Guerra de África (Impr. de M. Álvarez, Madrid, 1860) e Historia orgánica de los hospitales $y$ ambulancias militares (Impr. A. Cuadrado. Ciudad Rodrigo, 1880).

- Nicasio Landa con Campaña de Marruecos. Memorias de un Médico Militar (Impr. de M. Álvarez, Madrid, 1860).

- Ramón Hernández Poggio con Práctica quirúrgica de los médicos militares españoles en la última guerra de Marruecos. (Rev. de San. Mil. Esp. y Extranjera; serie de artículos desde el $\mathrm{n}^{\circ} 11$ del 15.06.1864 al $\mathrm{n}^{\circ}$ 48 del 25.12.1865), Tratamiento de las heridas por armas de fuego según la práctica de los médicos militares españoles (Madrid, 1872) y Medicina y Cirugía de los campos de batalla. T I (Impr. A. M. Fuentenebro, Madrid. 1853).

El autor, solo utiliza las obras de Población y Landa ignorando las de Poggio en las que se hace importantes referencias al uso de anestésicos.

Gómez Rodriguez afirma que desde que se descubrió el uso del cloroformo como anestésico en 1847 hasta 1859 en que comenzó la guerra, no se difundió su uso en España ya que parece poco el tiempo transcurrido para que la técnica llegara a España y estuviera generalizada".

La cronología histórica se encarga de desmentir documentalmente esta disparatada, equivocada e injusta suposición:

- En 1846, un año antes del descubrimiento del cloroformo, Morton había demostrado las mismas propiedades en el éter. Ese mismo año, Anastasio Chinchilla Piqueras, médico militar, ya menciona conocer las propiedades de los gases narcóticos ${ }^{2}$.

- Al año siguiente, el 27 de mayo de 1847 Rafael Gorria Azaldegui, Médico Mayor del Hospital Militar de la Victoria de Málaga ensayó la anestesia por éter en un soldado con una mano catastrófica a consecuencia de un disparo de fusil ${ }^{3}$.

- James Young Simpson publicó los resultados de su uso del cloroformo el 15 de octubre de $1847^{4}$ y en diciembre, Casares en Santiago de Compostela y el Catedrático de Clínica Quirúrgica, Vicente Guarnerio, en la misma ciudad, lo utilizaron por primera vez en España, el primero experimentalmente en animales y el segundo en una amputación de pene por un carcinoma. Solamente fueron necesarios dos meses escasos para aplicar semejante adelanto científico.

- En 1850, en el Hospital Militar de Mahón, León Anel, Jefe de Sanidad del Archipiélago relata ${ }^{5}$ dos operaciones quirúrgicas en las que emplea éter como anestésico y lo aplica con el aparato de eterización de Charriere enviado el año anterior por la Dirección General de Sanidad Militar ${ }^{6}$.

- En 1851 el Farmacéutico Militar del Hospital Militar de Sevilla, en un trabajo que hoy llamaríamos "de revisión" sobre el cloroformo, escribe: “... ... su aplicación ha producido constantemente el más feliz éxito en cuantas operaciones se ha hecho uso del mismo en este hospital (por el gefe (sic) local D. Jaime Camprecios). ......"”

- En 1852 el Jefe de Sanidad Militar de la Capitanía General de Andalucía, en su memoria anual ${ }^{8}$, relata una 


\section{Cartas al Director}

amputación de un miembro inferior por osteosarcoma dejando caer, como anecdótico, el haberla realizado

... ... sumergido el enfermo en una completa insensibilidad...... 9

- Durante la Guerra de Marruecos, la anestesia con cloroformo debió de ser la regla. Esta aseveración se desprende de lo publicado por Hernandez Poggio ${ }^{10,11}$. Poggio escribió a lo largo de 21 números (del n ${ }^{\circ} 11$ del 15 de junio de 1864 al $n^{\circ} 48$ del 25 de diciembre de 1865 con un total de 173 páginas) de la Revista de Sanidad Militar Española y Extranjera, un completo trabajo sobre "Práctica quirúrgica de los médicos militares españoles durante la última guerra de Marruecos". Siete años más tarde, en 1872, publica un compendio y ampliación de los artículos mencionados en su obra "Tratamiento de las heridas por armas de fuego según la práctica de los médicos militares españoles seguido de ligeras nociones de higiene militar en campaña” (Impr. A. G. Fuentenebro. Madrid, 1872).

Hernández Poggio (Op. cit.) relata como anestesia a tres soldados con cloroformo en el Hospital Militar del Revellin de Ceuta a los que iban a someter a amputaciones; incluso relata como uno de ellos (un prisionero marroquí), en el que la amputación se complica y se alarga en el tiempo, despierta $y$, sin quejarse, observa como se termina la amputación. Este autor asegura:

... ... haberse sometido a la acción del cloroformo la mayor parte de nuestros heridos operados.......

Como puede comprobarse, antes de la Guerra de África ya se utilizaba la anestesia por parte de los médicos militares, quienes hicieron de su práctica un proceder casi sistemático durante la contienda. No excluimos, sin embargo, casos puntuales de amputaciones en vivo sobre todo casos de urgencia vital en primera línea como el referido por Población y citado por el autor en su nota 12 de pie de página.

Sin desmentir la aseveración de Gómez Rodriguez sobre los usos farmacológicos del éter y del cloroformo (antiespasmódico y antiemético respectivamente) podemos afirmar que, al menos el cloroformo, se utilizó con asiduidad como anestésico.

Por último comentar lo que probablemente es un lapsus cala$m i$ : la anestesia con cloroformo que se aplicó a la reina Victoria en el parto de su octavo hijo, el príncipe Leopoldo de SajoniaCoburgo-Gotha fue en 1853 y no en 1857.

Francisco Martín Sierra

Coronel Médico (Reserva destinado)

Inspección General de Sanidad de la Defensa

\section{RÉPLICA DEL AUTOR}

Sr. Director:

Sobre la carta al director de la revista del Coronel Martín Sierra deseo hacer las siguientes consideraciones:

\section{Primera consideración.}

"El autor -dice Martín Sierra, refiriéndose a mi trabajocontabiliza entre médicos y farmacéuticos un total de 125 ". Está equivocado. Yo no contabilizo; quien lo hace es el doctor Población que indica que esa cifra se refiere a la "asistencia sanitaria inmediata y directa de un ejército de 50.000 hombres" Y añade: "Por otra parte, además del personal destinado en la unidades combatientes antes indicado, había que cubrir las necesidades de personal sanitario en los hospitales..." Ambas circunstancias constan literalmente en mi trabajo y, en mi referencia número 13, indico de donde se han sacado esos datos. (Población y Fernández, págs, 20-24) Ese "además” explicaría las diferencias entre los datos que da Población (no yo) y las que contabiliza el autor de la carta. Aprovechando el rifirrafe de esas cifras, el coronel Martín Sierra dice en su referencia ${ }^{\circ}$ 1 "Estamos elaborando un trabajo sobre el mismo tema que, con tanto tino, aborda Gómez Rodríguez'" Un irónico comentario con el que, sin duda, y por lo que dice después, pretende dar a entender lo contrario de lo que dice; esto es: "que con tanto desatino...."

\section{Segunda consideración}

Yo también deseo aportar a la cronología histórica algunos datos:

Tanto el doctor Población como el doctor Nicasio Landa, en sus respectivas obras sobre la guerra de Marruecos 1859-1860, se ocupan con gran detalle del material de campaña, camillas, vendajes, hilas, mochilas, botiquines, tiendas de campaña, furgones, medios de evacuación y trasporte, alimentos, y medicación; pero no hablan de la anestesia ni de los anestésicos. Parece incomprensible que ambos autores no hagan referencia explícita, esto es, clara y determinante, a una práctica revolucionaria que venía a trasformar profundamente la terapéutica quirúrgica.

En su obra "Historia de la anestesia en España 1847- 1940" (Arán Ediciones, Madrid 2005) sus autores, Avelino Franco Conde, Julián Álvarez Escudero y Joaquín Cortés Laíño, dicen: "La medicina española - más concretamente nuestra cirugía había sufrido un colapso total durante la primera mitad del siglo XIX (Pag. 106) y que "la culminación del proceso de asimilación de los anestésicos por nuestros cirujanos, su incorporación definitiva a las técnicas quirúrgicas", tuvo lugar a comienzos del último cuarto del siglo XIX. (Pag. 110)

Anastasio Chinchilla, Vicedirector del Cuerpo de Sanidad Militar decía en 1851 : "Al magnetismo sucedió el éter. En un principio se llegó a creer que era un medio seguro para adormecer la sensibilidad de los operados....Al éter sucedió el cloroformo. ¿Cuántos elogios se le han tributado al principio? Sin embargo ha perdido ya muchísimo. Sus ventajas corren a la par que sus inconvenientes" (Gazeta Médica de Madrid de 30 de julio).

En "La cirugía en España" de Francisco Vázquez Quevedo (Iatros ediciones Barcelona 1994) puede leerse: "Sea como fuere, la divulgación, aprendizaje y uso generalizado de la anestesia tardaría largos años en establecerse". (Pag. 77)

José $\mathrm{M}^{\mathrm{a}}$ Massóns, autor de la obra "Historia de la Sanidad Militar Española” (Ed. Pomares Corredor. Barcelona 1994) tra- 


\section{Cartas al Director}

ta de "Las campañas de Marruecos del siglo XIX" (Tomo II, pags. 217-228) y se extiende en numerosos detalles; pero nada dice del empleo de la anestesia en los hospitales militares en aquella campaña.

En resumen: Dos médicos protagonistas de la campaña ignoran en sus obras la existencia de la anestesia; unos historiadores de la anestesia en España dicen que la incorporación definitiva de la anestesia a la técnica quirúrgica tuvo lugar a comienzos del último cuarto del siglo XIX; un vicedirector del Cuerpo de Sanidad Militar duda en 1851 de la eficacia del éter y del cloroformo; un historiador moderno ignora la existencia de la anestesia en la campaña a que nos venimos refiriendo y otro dice que su uso generalizado tardaría largos años en establecerse. De estos datos deduzco que desde que se descubrió el uso del cloroformo como anestésico en 1847 hasta 1859 en que comenzó la guerra, no se difundió su uso en España ya que parece poco el tiempo transcurrido para que la técnica llegara a España y estuviera generalizada".

Esta suposición mía puede considerase errónea o equivocada; pero Martín Sierra la tacha, además, de disparatada e injusta.

El Coronel Martín Sierra dice que "Hernández Poggio relata cómo anestesia a tres soldados con cloroformo en el Hospital Militar de Revellín de Ceuta..." es uno de sus argumentos para deducir que "Durante la guerra de Marruecos la anestesia con cloroformo ‘debió de ser' la regla”. (Por cierto, lo que quizá quiere decir es que 'debió' ser la regla, porque el verbo deber acompañado de la partícula 'de' tiene, como se sabe, el significado de suposición o duda. Un lapsus calami, disculpable, sin duda).

\section{Tercera y última consideración}

Considero desacertadas y fuera de lugar las expresiones "disparatada", "injusta" y "con tanto tino"; carecen, a mi juicio, de valor argumental y tienen más de argumento ad hominem que de serena reflexión. "Suaviter in modo, fortiter in re", recomendaba Marco Fabio Quintiliano (S. I a.C.) Yo en esta contestación he procurado seguir la recomendación del pedagogo calagurritano.

Animo al coronel Martín Sierra a que culmine su trabajo. Cuanto más sepamos de aquella guerra más aumentará nuestra admiración hacia "Los hijos de Asclepio" (Título de mi segunda tesis doctoral) los beneméritos y sacrificados sanitarios militares. Le auguro y deseo un brillante éxito. Se lo merece por la pasión que ha puesto en el empeño.

Luis Gómez Rodríguez

Coronel farmacéutico retirado. De la Real Academia de doctores de España.

\section{NOTAS}

1. Estamos elaborando un trabajo sobre el mismo tema que, con tanto tino, aborda Gómez Rodriguez.

2. CHINCHILla PIQUERAS, A. Compendio de Cirugía. Ed. I. Boix. Madrid, 1846

3. FRANCO, A., ÁlVAREZ, J. y CORTÉS, J. Historia de la anestesia en España (1847-1940). Ed. Arán, Madrid, 2005. Pp. 43.

4. SIMPSON, J. Y. Account of a new anesthetic agent as substitute for sulphuric ether in surgery and midwifery. Comunicación a la Sociedad Médico-quirúrgica de Edimburgo. 15 de octubre de 1847.

5. ANEL, L. Memoria. Biblioteca Medico-Castrense Española, pp. 33-36. T III. Madrid, 1851.

6. Suponemos que si la Dirección General de Sanidad Militar surtía a los Hospitales Militares con instrumental para aplicar anestesia, es que ésta, era una práctica habitual.

7. TORREJIMENO, J. Cloroformo y colodión. Biblioteca Médico-Castrense española. T III. Madrid, 1851. Pp. 274.

8. DIAZ DEL CASTILLO, G. Memoria correspondiente al año 1852. Biblioteca Médico-Castrense. T VII. Madrid, 1852

9. Ibídem. pp. 157.

10. HERNANDEZ POGGIO, R. Práctica quirúrgica de los médicos militares españoles en la última guerra de Marruecos. Rev. de San. Mil. Esp. y Extranjera. 24, 1864. Pp. 579-581.

11. HERNANDEZ POGGIO, R. Tratamiento de las heridas por armas de fuego según la práctica de los médicos militares españoles. Madrid, 1872. 